\title{
SULFATE REMOVAL IN BIOCHEMICAL REACTORS AND SCRUBBERS TREATING NEUTRAL LOW-METAL CONCENTRATION MIW $^{1}$
}

\author{
Guadalupe Fattore, ${ }^{2}$ James Gusek, ${ }^{3}$ Thomas Clark, ${ }^{4}$ and Lee Josselyn ${ }^{3}$
}

\begin{abstract}
Sulfate and metals are commonly found in mining influenced water (MIW). A biochemical reactor (BCR) is an established technology that can remove sulfate and metals. Three organic mixtures were bench-tested for approximately six months to decrease sulfate concentration in a circum-neutral $\mathrm{pH}$ MIW containing low metal concentrations. Organic materials included wood pellets, oat straw, biochar, and manure as an inoculum. These were blended with limestonedolomite sand. Additionally, sulfide polishing units (SPUs), which were charged with native soil from the site, zero valent iron (ZVI), or magnetite, were evaluated for removal of dissolved sulfide discharged from each of the BCRs. Median MIW influent contained about $3000 \mathrm{mg} / \mathrm{L}$ of sulfate and very low concentrations of metals. The flow rates varied from 144 to $1,231 \mathrm{~mL} /$ day. Among all the BCRs tested, the hydraulic retention times varied from 5 to 75 days. All BCRs demonstrated similar removal rates of about 1.3 (BCR 1), 1.4 (BCR 2), and 1.6 (BCR 3) $\mathrm{mol} \mathrm{SO}_{4}{ }^{-2} / \mathrm{m}^{3}$-day during the last week of testing. While the SPUs removed dissolved sulfide from the BCR effluents as expected, they removed sulfate as well. Dissolved organic carbon in the BCR effluents promoted sulfatereducing microbial activity in the SPUs where the inorganic materials functioned as a solid support for the microbial community. The magnetite was not an effective medium for post-BCR sulfate removal. Sulfate removal efficiencies in the BCRs were 55\% (BCR 1), 57\% (BCR 2), and 67\% (BCR 3) during the final week of the bench-scale testing. Sulfate removal in the SPUs (from the BCRs effluents) was $35 \%$ and $37 \%$, for SPU 1 and SPU 2, respectively. Novel reactor charging configurations in single units may therefore be much more effective and efficient than approaches exclusively using lignocellulosic or inert supports. Sulfate reducing microbial populations were still increasing when the test was concluded.
\end{abstract}

Additional Key Words: BCR; Sulfate; Organic Mixture.

${ }^{1}$ Paper presented at the 2017 National Meeting of the American Society of Mining and Reclamation, Morgantown, WV What's Next for Reclamation April 9-13, 2017. R.I. Barnhisel (Ed.) Published by ASMR, 1305 Weathervane, Champaign, IL 61821

${ }^{2}$ Project Engineer, Sovereign Consulting Inc. 12687 W. Cedar Dr., \#305, Lakewood, CO 80228;

${ }^{3}$ Sovereign Consulting, Lakewood, CO;

${ }^{4}$ Solfatara Laboratories, Golden, CO

Journal American Society of Mining and Reclamation, 2017 Volume 6, Issue 2 pp 1-18

DOI: http://doi.org/10.21000/JASMR17020001 


\section{$\underline{\text { Introduction }}$}

Sovereign Consulting Inc. (Sovereign) and Solfatara Laboratories LLC (Solfatara) conducted bench-scale tests to evaluate the removal of sulfate from a confidential site's mine influenced water to concentrations less than 250 milligrams per liter $(\mathrm{mg} / \mathrm{L})$. This preliminary assessment was conducted to evaluate whether using biochemical reactor (BCR) technology followed by passive sulfide polishing units (SPU) could meet the sulfate requirements and to assess the performance of various media in both passive treatment units.

Mine influenced water (MIW) used in the bench testing was alkaline (pH around 8.1) and contained approximately $3,000 \mathrm{mg} / \mathrm{L}$ of sulfate and very low concentrations of metals. It was derived from a waste rock dump containing rock that exhibited net-alkaline acid base accounting (ABA) geochemistry.

The primary objective of a bench-scale test was to identify regionally-available organic materials and mixtures that may be suitable for use in the full-scale BCR under variable flow rates. Three organic mixtures containing different ratios of straw, wood pellets, and biochar were tested; manure provided the microbial inoculum. The biochar, sourced from pine beetle-killed trees in Colorado, was not local to the project site. The inorganic fraction of the three mixtures included limestone-dolomite sand. Additionally, three inorganic materials were evaluated as a means of scrubbing excess hydrogen sulfide/sulfide ion from the BCR effluents. The scrubber reactors or sulfide polishing units (SPUs) were charged with native soil from the site, scrap metal (zero valent iron $[\mathrm{ZVI}]$ ) or magnetite, and operated in series following a single BCR.

Sulfate reduction is a microbiological reaction that occurs under anaerobic conditions. Sulfate is reduced to hydrogen sulfide and bicarbonate ion by a group of sulfate-reducing bacteria (Desulfovibrio, for example) which utilize short chain organic acids and alcohols as carbon sources and sulfate as an oxidant (Equation 1). The general reactions, which have been cited in numerous publications and are considered conventional wisdom, can be represented as:

$$
\mathrm{SO}_{4}^{-2}+2 \mathrm{CH}_{2} \mathrm{O} \rightarrow \mathrm{HS}^{-}+2 \mathrm{HCO}_{3}^{-}+\mathrm{H}^{+}
$$

The hydrogen sulfide reacts with metals in solution $\left(\mathrm{Me}^{+2}\right)$ to form insoluble metal sulfide (MeS) precipitates (Equation 2). $\mathrm{Me}^{+2}$ is a divalent metal and $\mathrm{MeS}$ is the metal precipitate.

$$
\mathrm{Me}^{+2}+\mathrm{HS}^{-} \rightarrow \mathrm{MeS}+\mathrm{H}^{+}
$$


The carbon source is generally provided by a mixture of solid substrates (e.g., wood chips, wood pellets, straw) to provide both short-term and long-term carbon sources that insure a quick start up as well as steady prolonged treatment. BCR substrates also typically contain a crushed limestone component (even for net alkaline MIW) to suppress fermenting bacteria that can lower the $\mathrm{pH}$ and protect the bacterial community against $\mathrm{pH}$ or acidity excursions (ITRC, 2013).

The secondary objective of the study was to determine which of the three sulfide-sequestering materials (site soil, scrap metal, magnetite) in the SPUs were more efficient at removing residual $\mathrm{H}_{2} \mathrm{~S}$. Site soil appeared to exhibit natural sulfide-sequestering characteristics based on the anecdotal performance of the existing site treatment system. Dissolved iron (generated by anaerobic corrosion of iron [Equation 3, page 9]) released from the scrap metal (zero valent iron, or ZVI) will remove dissolved sulfide from the water by precipitating iron sulfide (ITRC, 2013). Magnetite $\left(\mathrm{Fe}^{2+} \mathrm{Fe}^{3+}{ }_{2} \mathrm{O}_{4}\right)$ has also been used as a source of sacrificial metal to scrub dissolved sulfide from a BCR (Blumenstein et al., 2013) and so it was also assessed here. Each material was evaluated in an individual SPU. In addition, the longevity of the BCRs mixture was evaluated.

The result of using various organic/inorganic material blends in the BCRs and of coupling these reactors to the SPUs are presented here.

\section{Material and Methods}

The three BCRs material mixtures and the logic behind their selection are shown in Table 1.

The three SPUs materials and their respective quantities and sources are indicated in Table 2.

The bench scale Passive Treatment System (PTS) process diagram is shown in Fig. 1 and in a photo in Fig. 2.

The logistics of procuring MIW from the site were challenging. The desired source site of influent MIW was inaccessible during the winter. Therefore, the project initially used diluted water from another nearby mine site that had a higher concentration of sulfate and very little metals. This surrogate MIW source was used for six weeks of BCR incubation and an additional 15 weeks of BCR operation. However, the final five weeks of BCR steady-state operation used the actual mine site MIW as a feed solution. 
Journal American Society of Mining and Reclamation, 2017 Vol.6, No.2

Table 1. Bench Scale Mixtures Proportions of Components by Weight (AsReceived).

\begin{tabular}{lccc}
\hline Material $\dagger$ & BCR 1 & BCR 2 & BCR 3 \\
\hline Biochar $^{1}$ & $0 \%$ & $0 \%$ & $10 \%$ \\
Wood Pellets $^{2}$ & $0 \%$ & $20 \%$ & $40 \%$ \\
Limestone $^{3}$ & $10 \%$ & $10 \%$ & $10 \%$ \\
Oat Straw $^{4}$ & $85 \%$ & $65 \%$ & $35 \%$ \\
Animal Manure & $5 \%$ & $5 \%$ & $5 \%$ \\
Total & $100 \%$ & $100 \%$ & $100 \%$ \\
Logic & Baseline & Straw + Pellets & $50-50$ Straw+Pellets+Biochar \\
Mass (kg) & 1.9 & 2.4 & 4.2 \\
\hline
\end{tabular}

$\dagger$ Material Sources

${ }^{1}$ Prospector Soils, LLC, Olathe, $\mathrm{CO}^{2}$ New Earth Pellets (pine bark beetle killed tree), Lakewood, CO

${ }^{3}$ Local site limestone source

${ }^{4}$ Local vendor near the site

${ }^{5}$ Initial Mix: local deer herd, Lakewood CO. Cow manure from Golden, $\mathrm{CO}$ for re-inoculation

Note: the limestone component was included to suppress substrate fermentation reactions and was not expected to be consumed faster than the organic materials in the alkaline influent MIW. As limestone dissolution rates were inconsequential to the results of the test, the limestone was not characterized in any detail (e.g., $\mathrm{Ca}$, $\mathrm{Mg}$, $\mathrm{Si}$, and $\mathrm{CO}_{3}$ analyses).

Table 2. Sulfide-Sequestering Materials Quantities and Sources.

\begin{tabular}{lccc}
\hline Material & SPUs & $\begin{array}{c}\text { Quantities }^{1} \\
(\mathrm{~kg})\end{array}$ & $\begin{array}{c}\text { Material } \\
\text { Sources }\end{array}$ \\
\hline Soil/Rock & SPU 1 & 1.9 & Site \\
Scrap Metal & SPU 2 & 6.1 & Steel Cans ${ }^{2}$ \\
Magnetite & SPU 3 & 4.1 & Laguna Clay Pottery Supply \\
\end{tabular}

${ }^{1}$ Quantities were determined by volume to provide nearly identical pore volumes so that hydraulic retention times in the SPUs were identical to each other at all flow rates.

${ }^{2}$ The cans (from food packaging) were quick-frozen with liquid nitrogen and reduced to $6 \mathrm{~mm}$ or smaller sized pieces in a hammer mill.

${ }^{3}$ This material may have contained a residual salt contaminant that introduced an unexpected bias. 


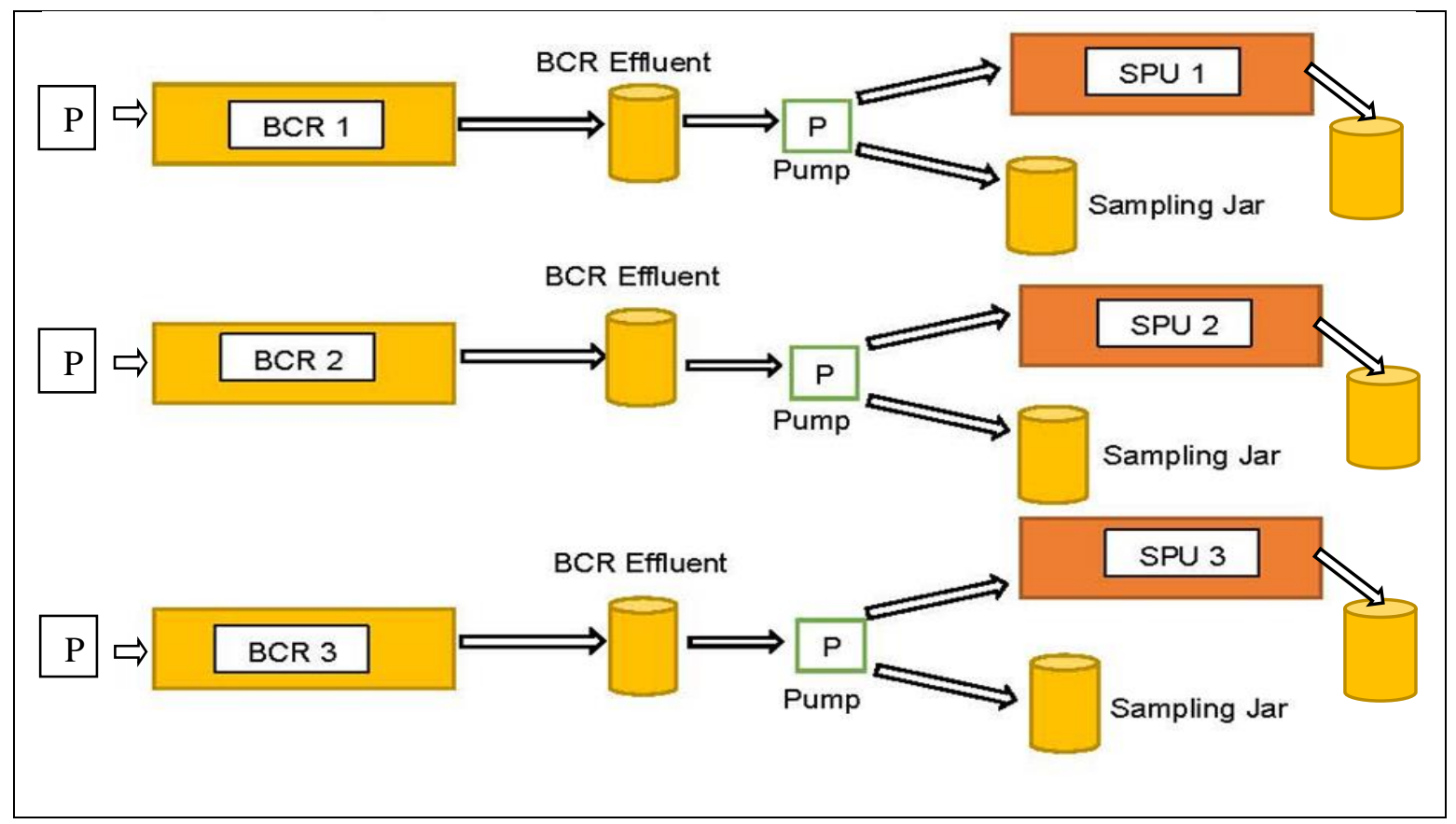

Figure 1. Bench Scale Passive Treatment Process Flow Diagram.

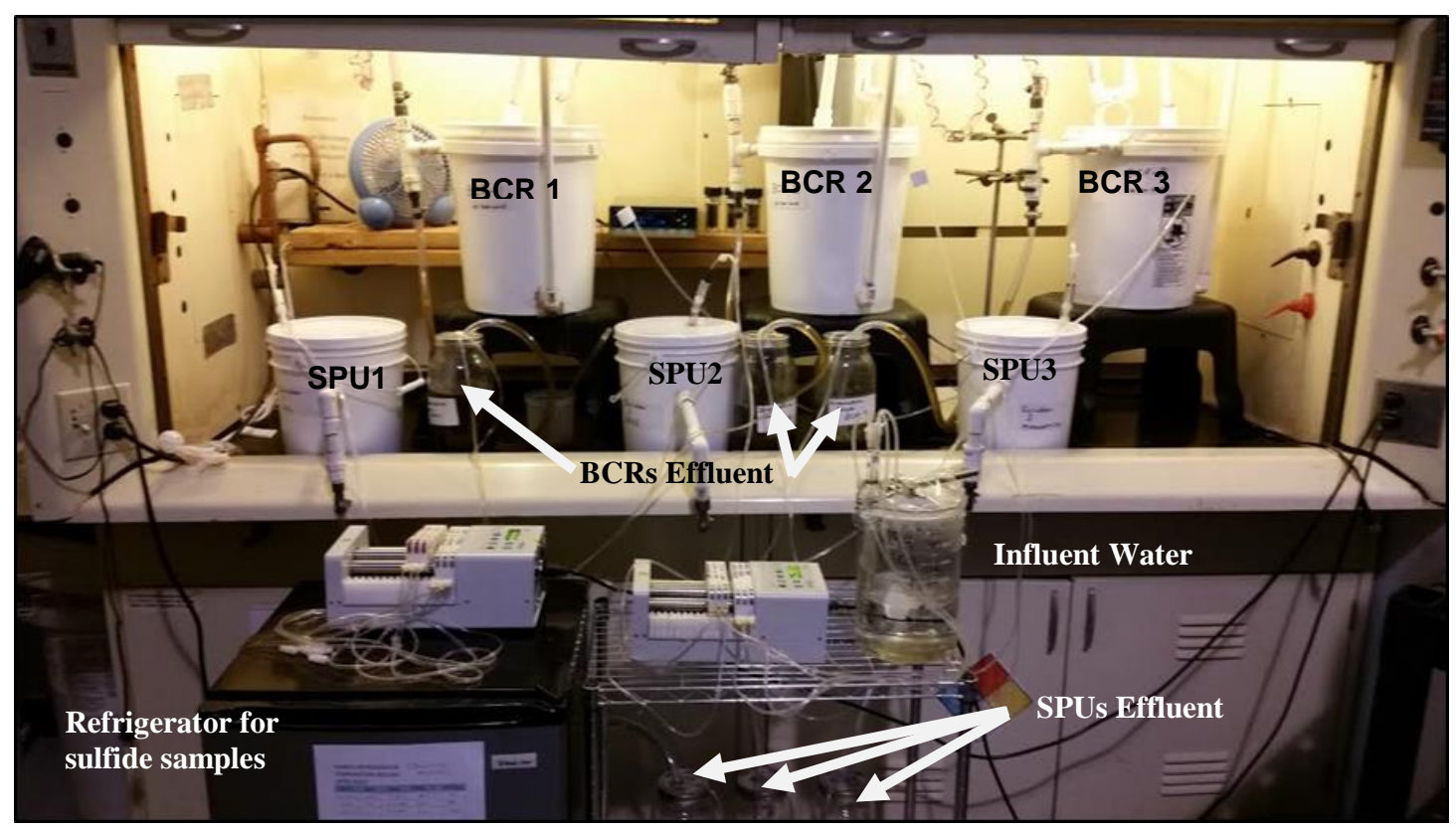

Figure 2. Bench Scale Passive Treatment at Solfatara Laboratories LLC.

Solfatara collected the field data and bench test water samples and sent them to a commercial analytical lab and to the Colorado School of Mines (CSM). At intervals, replicate quality assurance (QA) samples were forwarded to a second commercial analytical laboratory. 
The sampling and analysis plan consisted initially of 12 sampling events (one per week) after commissioning. An extension (eight additional weeks) to the testing and sampling plan was necessary because the BCRs still appeared to be maturing after 12 weeks (sulfate reduction rates had yet to "plateau"). Samples were collected from the common BCR influent (MIW water), BCR effluents, and SPU effluents after the BCRs had been initially incubated for five to six weeks. The SPUs were expected to receive BCR effluent immediately upon system commissioning; however, this action was delayed until sulfate reduction was confirmed in the BCRs, week 10 for SPU2 and 3, and week 9 for SPU1.

The effluent of the BCRs was pumped continually into a two-liter closed glass vessel. At the end of each week, the samples were analyzed for sulfate and other parameters including: total and dissolved ICP metals (Al, As, Ba, Cd, Cu, Cr, Fe, Mn, Ni, Se, Tl, and Zn), Ca, Mg, Na, total dissolved solids (TDS), and total organic carbon (TOC). Sulfide samples were typically pumped continuously from the effluent-receiving vessel to a refrigerator containing sample bottles amended with chemical preservative. Field parameters included those indicative of desirable microbial activity: sulfate, microbial population using SRB-BART growth tubes (HACH, 2013), specific conductivity, alkalinity (HACH, Method 8203), $\mathrm{pH}$, oxidation reduction potential (ORP), temperature, color, and odor. Samples were preserved and stored in accordance with standard protocols.

In addition, samples of straw, pellets, and biochar were collected for loss on ignition testing (LOI). The LOI is used to determine the carbon content of the substrate samples and the analytical results were used to estimate the longevity of the substrate. Soil/rock collected at the Site was subjected to acid-base accounting (ABA), meteoric water mobility procedure (MWMP), and mineralogical analysis (X-Ray Diffraction [XRD]). ABA analysis results were used to identify how much sulfur (sulfide and sulfate) was associated with the native soil. The purpose of the MWMP was to evaluate the potential for dissolution and mobility of selected constituents from the native soil by meteoric water. The XRD test results were used to identify the mineralogy of the soil/rock and help to identify the compounds that could form upon exposure to sulfide. 


\section{$\underline{\text { Results and Discussion }}$}

Biochemical Reactors (BCRs) and Sulfide Polishing Units (SPUs)

To recap, after filling the reactors with site water, the BCRs were incubated for a period of five to six weeks to allow development of carbon-mobilizing and sulfate-reducing microbial populations. The BCRs were then placed in continuous flow mode at a low flow rate. Influent flow rates, BCRs and SPUs configuration and performance are summarized in Figs. 3 and 4. Figure 3 presents sulfate removal in terms of bulk volumetric kinetics of the substrate (mol SO${ }^{-2} / \mathrm{m}^{3}$-day), while Fig. 4 illustrates performance in terms of residual sulfate concentrations $\left(\mathrm{mg} / \mathrm{L} \mathrm{SO}_{4}{ }^{-2}\right)$.

\section{Sulfate Removal}

The bench scale system configuration illustrated in Fig. 1 was reconfigured based on the sulfate analytical results of the Week 13 sampling event. BCR 1 and SPU 2 were performing better than the other units and Sovereign believed that pairing BCR 1 with SPU 2 would result in better combined sulfate reduction. After the switch, BCR 1 and SPU 2 continued to perform well but not as expected; performance was not additive. At the end of the testing ( 20 weeks of steady-state flow), all BCRs demonstrated similar bulk sulfate kinetic removal rates and concentrations (Fig. 3 and 4). It is interesting to note that the sulfate removal rate for BCR 1 was double when comparing weeks 10 and 20 (Fig. 3) while in Fig. 4, the effluent concentrations in weeks 10 and 20 were the same. This can be attributable to the differences in flow rate: $20.8 \mathrm{ml}^{-h^{-1}}$ in week 10 and $51.3 \mathrm{ml}^{-\mathrm{hr}^{-1}}$ in week 20 .

As noted in Fig. 3 and 4, BCR 3 and 2 performed similarly, even though the relative abundance of wood pellets in the BCR3 substrate (40\%) was double that in BCR 2 (20\%). Additionally, BCR 3 contained approximately one-half the quantity of more easily degradable oat straw as BCR 2 (35\% vs. 65\%, respectively). However, the BCR 3 sulfate reduction rate was nearly identical to that in BCR 2 (Fig. 3). Though biochar surfaces were not directly examined, LOI test results suggest that carbon was being consumed at a higher rate, and therefore more excess carbon was being discharged in the BCR 3 effluent, compared to BCR 2. This condition may offer "carryover" sulfate reduction possibilities in SPUs as discussed below. 
Journal American Society of Mining and Reclamation, 2017 Vol.6, No.2

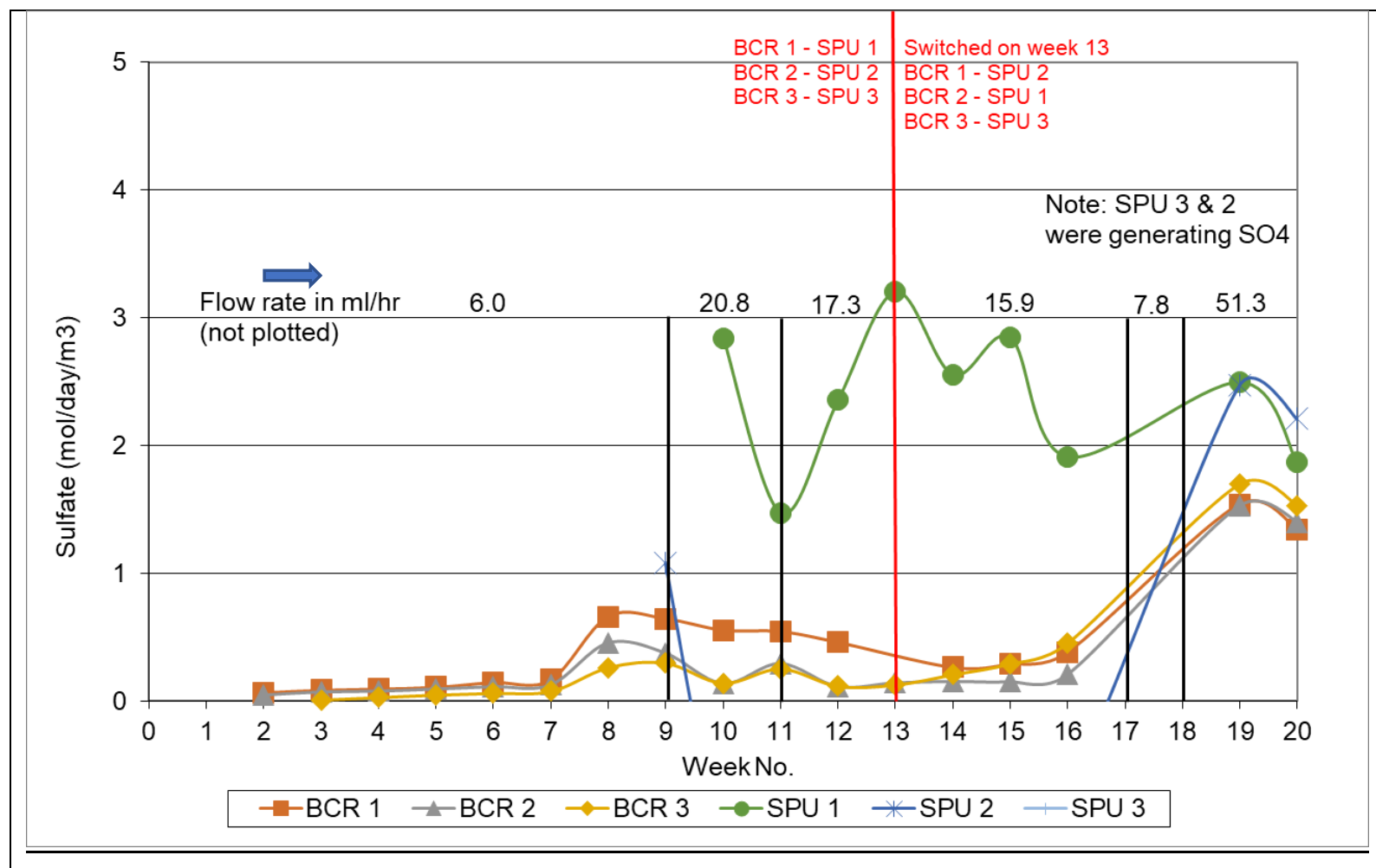

Figure 3. Sulfate Removal Rate during Continuous Variable Flow Mode

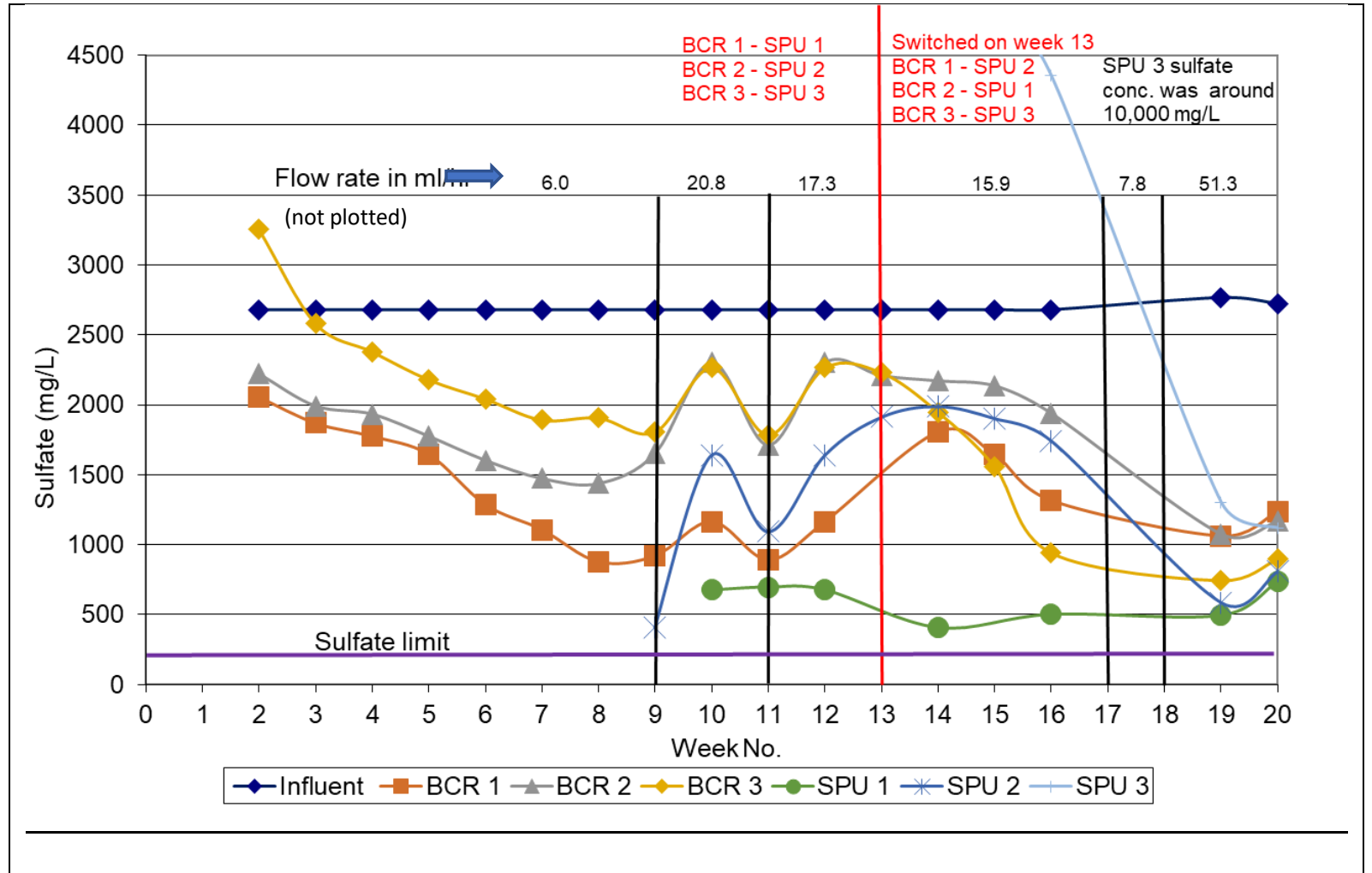

Figure 4. Sulfate Concentration during Continuous Variable Flow Mode. 
Biochar behaves as an "electron shuttle" (Xu et al., 2016) and this property prompted its inclusion as a possible catalyst to improve BCR performance. Therefore, it was inferred that the biochar included in the BCR 3 substrate was responsible for the increased sulfate removal efficiency by increasing carbon availability.

Due to the presence of total organic carbon in the BCR effluents, "carry-over" sulfate reduction continued in the SPUs. Interestingly, SPU 2 (scrap metal) demonstrated a removal rate similar to SPU1 (soil/rock) in the final two weeks of sampling. ZVI is a strong reductant and when exposed to organic carbon, enhances the environment for successful growth of sulfate-reducing bacteria (SRB), as reported by Legrand et al. (2014). This is partly a result of the reduction potential of water during anaerobic corrosion of ZVI which can generate neutral or alkaline conditions (preferred by SRB) in mine drainage treatment systems (Wilkin and McNeil, 2003). A reaction for the anaerobic corrosion of iron is indicated in Equation 3.

$$
\mathrm{Fe}^{0}+2 \mathrm{H}_{2} \mathrm{O} \rightarrow \mathrm{Fe}^{+2}+\mathrm{H}_{2}+2 \mathrm{OH}^{-}
$$

Hydrogen gas released in this reaction may be used by SRB in addition to organic carbon as an electron donor (Abram and Nedwell, 1978). Thus, when an organic carbon source is not ideally suited for use by bacteria, an alternative electron donor is still available (Legrand et al., 2014).

Prior to the last two weeks of the laboratory bench testing of the BCR operation, sulfate levels increased in SPU 2 and SPU 3 compared to their respective BCR effluent feed waters (Fig. 4). The reasons for this observation in BCR 2 are uncertain but they may be due to interferences that allowed the kinetics of bacterial oxidation of native sulfur $\left(S^{0}\right)$ to sulfate (Pelczar et al., 1977) to out-pace the sulfide-sequestering effects of the SPU media. This interference appears to have abated in the final two weeks of the SPU 2 operation. The observations in SPU 3 are counterintuitive. The excess amounts of dissolved organic carbon present in the BCR 3 effluent due to the suspected benefits of biochar in the BCR 3 substrate mixture, could have supported additional sulfate reduction but it was not observed. However, this condition could have been masked in SPU 3 due to the presence of a secondary source of sulfate, adding a note of caution to the sourcing of materials. 


\section{Metals Concentrations}

The Multi-Element Scans (ICP/AES) results of the last week of testing (week 20) are presented in Table 3. It is interesting to note that final effluent of BCRs/SPUs configurations had slightly higher concentrations of $\mathrm{Ba}, \mathrm{Fe}, \mathrm{Mn}$, and $\mathrm{Tl}$ than the feed water. However, the effluent metals concentrations were typically less than ten times the lab detection limit (where data accuracy is more questionable and the relative difference between points cannot reliably be assessed).

BCR 1/SPU 2. This configuration produced a final effluent with slightly higher concentrations of $\mathrm{Fe}, \mathrm{Mn}$, and $\mathrm{Tl}$ than the feed water, resulting in part from the solution contact with the ZVI charge in SPU 2. Barium slightly increased in concentration as solution passed through the BCR 1, but decreased to the feed value upon passing thorough SPU 2.

BCR 2/SPU 1. This configuration produced an effluent that showed, in comparison to the influent, a slightly increased concentration of $\mathrm{Fe}, \mathrm{Mn}, \mathrm{Tl}$, and $\mathrm{Ba}$. In this case, $\mathrm{Mn}$ and $\mathrm{Ba}$ increased as solution passed through the BCR 2 and remained elevated in concentration as the BCR 2 effluent passed through the SPU 1, but sorption or precipitation in SPU 1 (native soil) resulted in a smaller increase than what would have been seen with the BCR 1 alone. In addition, SPU 1 effluent had an increase in As concentration. The results of the Meteoric Water Mobility Procedure (MWMP) performed on one site soil sample (the same soil used in the SPU 1) showed that the site soil has the potential to mobilize arsenic $(0.05 \mathrm{mg} / \mathrm{L})$. However, the concentration of As in the SPU 1 effluent is higher than the soil. This may have been due to undetermined equilibrium conditions in the test unit.

BCR 3/SPU 3. BCR 3 effluent showed concentrations of Ba, Fe, Mn, and Tl slightly higher than the feed water and BCR 1 and BCR 2. SPU 3, although still operating, had been abandoned as a viable choice and so analytical work was discontinued due to the increase in sulfate compared with the influent water.

\section{$\underline{\text { BCRs Media Results }}$}

Samples of oat straw, wood pellets, and biochar were collected for loss on ignition (LOI) testing. The LOI values are used to determine the carbon content of the substrate mixtures and they were used to calculate the longevity of carbon portion in the substrate. The oat straw, wood pellets, and the biochar LOI values for the samples (as-received) were 90.3\% 99.4\%, and 92.4\%, respectively. 
Table 3. Dissolved Metal Concentrations - Week 20.

\begin{tabular}{lcccccc}
\hline Date & \multicolumn{2}{c}{$6 / 25 / 2015$} & \multicolumn{5}{c}{$7 / 23 / 2015$} \\
Parameter & Influent & BCR 1 & SPU 2 & BCR 2 & SPU 1 & BCR 3 \\
\hline $\mathrm{Al}$ & $<1.00$ & $<1.00$ & $<1.00$ & $<1.00$ & $<1.00$ & $<1.00$ \\
$\mathrm{As}$ & $<0.25$ & $<0.25$ & $<0.25$ & $<0.25$ & 2.29 & $<0.25$ \\
$\mathrm{Ba}$ & $<0.10$ & $\mathbf{0 . 1 2 8}$ & $<0.10$ & $\mathbf{0 . 1 4 4}$ & $\mathbf{0 . 1 0 7}$ & $\mathbf{0 . 2 6 7}$ \\
$\mathrm{Ca}$ & 426 & 358 & 34.7 & 365 & 266 & 364 \\
$\mathrm{Cd}$ & $<0.10$ & $<0.10$ & $<0.10$ & $<0.10$ & $<0.10$ & $<0.10$ \\
$\mathrm{Cr}$ & $<0.10$ & $<0.10$ & $<0.10$ & $<0.10$ & $<0.10$ & $<0.10$ \\
$\mathrm{Cu}$ & $<0.10$ & $<0.10$ & $<0.10$ & $<0.10$ & $<0.10$ & $<0.10$ \\
$\mathrm{Fe}$ & $<0.10$ & $\mathbf{0 . 1 2 3}$ & $\mathbf{0 . 6 7 1}$ & $\mathbf{0 . 1 0 4}$ & $\mathbf{0 . 1 7 4}$ & $\mathbf{0 . 1 0 7}$ \\
$\mathrm{K}$ & $<10$ & 129 & 172 & 138 & 207 & 158 \\
$\mathrm{Mg}$ & 465 & 560 & 570 & 552 & 583 & 558 \\
$\mathrm{Mn}$ & $<0.05$ & $\mathbf{0 . 0 5 2}$ & $\mathbf{0 . 0 8 5}$ & $\mathbf{0 . 1 8 7}$ & $\mathbf{0 . 1 2 4}$ & $\mathbf{0 . 8 3 8}$ \\
$\mathrm{Na}$ & 19 & 53 & 63 & 59 & 73 & 42 \\
$\mathrm{Ni}$ & $<0.30$ & $<0.30$ & $<0.30$ & $<0.30$ & $<0.30$ & $<0.30$ \\
$\mathrm{~Pb}$ & $<0.50$ & $<0.50$ & $<0.50$ & $<0.50$ & $<0.50$ & 0.50 \\
$\mathrm{Se}$ & $<0.50$ & $<0.50$ & $<0.50$ & $<0.50$ & $<0.50$ & 0.50 \\
$\mathrm{Tl}$ & $<0.10$ & $\mathbf{0 . 1 5 5}$ & $\mathbf{0 . 1 6 3}$ & $\mathbf{0 . 1 2 8}$ & $\mathbf{0 . 2 4 6}$ & $\mathbf{0 . 1 9 7}$ \\
$\mathrm{Zn}$ & $<0.30$ & $<0.30$ & $<0.30$ & $<0.30$ & $<0.30$ & $<0.30$ \\
\hline
\end{tabular}

Note: Values in bold and italic are greater than the influent water.

$\underline{\text { SPU Media Results }}$

Soil/rock. A sample of soil/rock was collected from the site and subjected to ABA and MWMP analysis. The results indicate that the soil has very little total sulfur; consequently, sulfate and sulfide concentrations are low. The soil/rock media was viable candidate media for sulfur sequestration. The MWMP results indicate that there was a very low potential for the native soil/rock to release metals ( $\mathrm{Al}, \mathrm{As}, \mathrm{Cu}, \mathrm{Fe}, \mathrm{Mn}$, and $\mathrm{Zn}$ ).

In addition, the soil/rock sample was subjected to XRD testing. The results indicate that the major rock forming mineral was quartz. Calcite, dolomite, phyllosilicate (possibly phlogopite), and other phyllosilicates (dickite, or kaolinite, or both) are also present. Lime and ankerite are possibly present. Discussions in the literature (Li et al., 1998) suggest that phyllosilicates might be geochemically altered by dissolved sulfide into mineral phases that can sequester sulfur/sulfide 
contained in the BCR effluent. This hypothesis should be investigated further to validate the concept that the native soil and rock at the site can provide a long-term source of sulfursequestering media.

The analytical results from the effluent of the SPU 1 suggest that the soil/rock media exhibited sulfide scrubbing characteristics. The soil/rock media functioned as a solid support for the microbial community that supported supplemental sulfate reduction.

Scrap Metal (ZVI). The analytical results from the effluent of the SPU 2 suggest that the scrap metal media exhibited sulfide scrubbing characteristics comparable to the native soil and rock in SPU 1 with minor variances. The scrap metal "matrix" appeared to function as a media that supported supplemental sulfate reduction as well. If necessary, it could substitute for or be used as an amendment to native soil and rock.

Magnetite. The magnetite material did not appear to sequester sulfide or reduce sulfate during the test program due to unforeseen sulfate contamination. Magnetite usage as a source of sacrificial metal to scrub dissolved sulfide from a BCR was reported by Blumenstein et al., 2013. Therefore, it should not be dismissed as a potential source of sacrificial iron. There appear to be waste streams of this material associated with steel slag processing plants in Utah that might be considered in the future. Additional testing would be required to assess the appropriateness of applying a magnetite amendment to site soils to enhance the sequestration of sulfide.

\section{$\underline{\text { Sulfate-Reducing Microbial Populations }}$}

Decisions to change the original schedule were based on microbiological and solution data. Specifically, the BCRs were subjected to: 1) an incubation period of 5 to 6 weeks; 2) a period with low flow (6 weeks) and correspondingly low sulfate loadings while demonstrating relatively low rates of sulfate reduction; 3 ) a period of moderate flow (9 weeks); 4) a one-week period of no flow; and 5) a period of operation beyond ( 3 weeks) the original projected time frame. Speculation based on the data sets that indicated an abundance of dissolved organic carbon in the BCRs effluents lead to the conclusion that BCRs 1 and 3 were limited more by the sulfate-reducing populations than that portion of the microbial consortium responsible for mobilizing available carbon from the organic-based feed materials. In contrast, BCR 2 performance appears to have been limited by a paucity of both microbial groups. 
There was no convenient growth-dependent technique available for monitoring the many carbon mobilizing and transforming anaerobic microbial clades populating the BCRs. We were left with monitoring organic carbon as an indirect measure of their efficacy in digesting the lignocellulosic feeds. However, sulfate reducing populations were monitored directly.

Solution taken directly from the BCRs effluent tube (not from the intermediate sample bottles collecting effluent) was periodically assessed for sulfate-reducing (SRB) populations. Figure 5 illustrates a growth-dependent test using BCR effluents collected on Day 97 (week 8) - more than three months after reactor charging and two months following the onset of low rate continuous flow. The lack of a black $\mathrm{FeS}_{\mathrm{x}}$ precipitate in the tube corresponding to BCR 2 (middle tube) is indicative of a lack of hydrogen sulfide production due to a low population density of sulfatereducing bacteria.

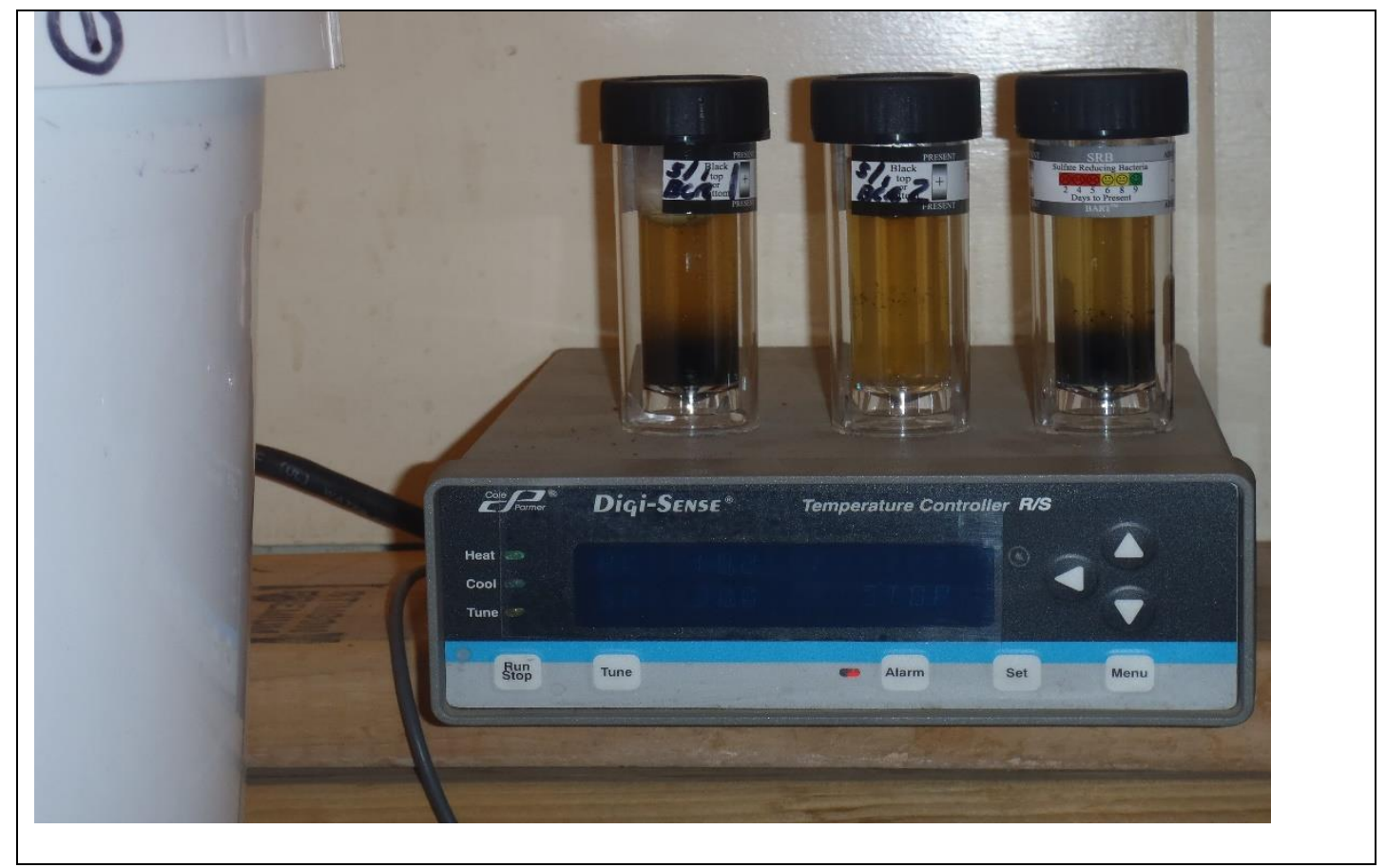

Figure 5. Day 97 Sulfate-reducer Test - BCR 1, BCR 2, and BCR 3 Effluent.

Even after three months, BCR 2 had a substantially lower SRB population than either BCR 1 or BCR 3 (Fig. 6). Unfortunately, the test loses resolution at SRB cell concentrations exceeding $6.8 \times 10^{6}$ cells per $\mathrm{mL}$ so it is possible (likely) that the actual cell numbers above that limit on days 97 and 163 were much higher than shown. That the SRB populations were found to be increasing in each of the three BCRs (after re-inoculation) indicates that the reactors were still maturing and 
had likely not reached their full sulfate-reducing capacity when the test program was terminated at 181 days.

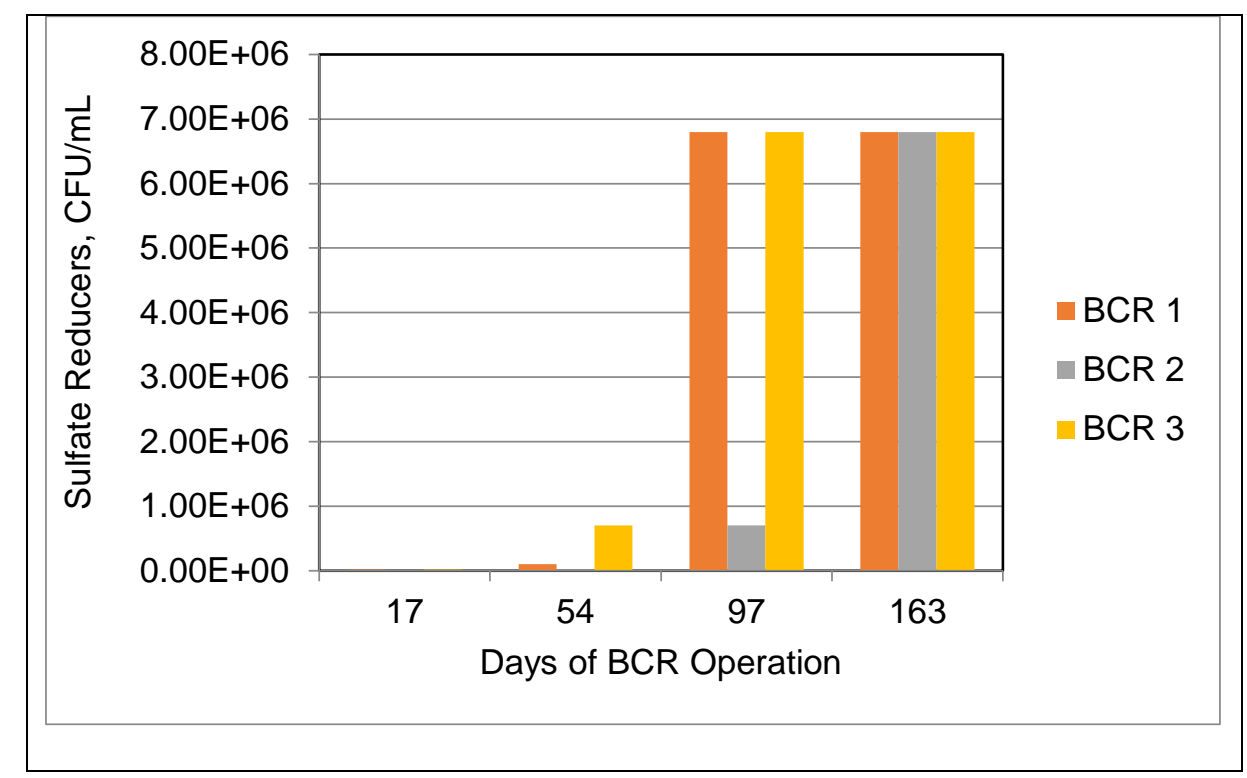

Figure 6. BCR Effluent Sulfate-Reducing Microbial Population (CFU/mL).

\section{Substrate Longevity}

The substrate has a finite life and the estimated substrate longevity was based on sulfate loading and carbon consumption. The bench scale test results indicate that the rate of carbon consumption and loss (unused carbon in the effluent as TOC) are the primary governing factors in the calculation of the longevity of the substrate. Note that two moles of carbon are required to reduce one mole of sulfate to one mole of hydrogen sulfide (Equation 1). As indicated in Table 4, BCR 1, BCR 2, and BCR 3 contained about $0.4,0.6$, and $1.2 \mathrm{~kg}$ of carbon, respectively, of which it was conservatively assumed that only $50 \%$ was biologically available. The average carbon consumption rate in BCR 1, BCR 2, and BCR 3 was about 0.16, 0.11, and 0.13 grams/day, respectively. At these consumption rates (assuming TOC losses are negligible and the rate does not depend on the TOC concentration; i.e., zero-order kinetics), the BCR 1, BCR 2, and BCR 3 carbon "reservoirs" would be depleted in about 3.0, 5.2, and 9.1 years, respectively, as the organic degradation "reaction front" advances from the influent zone of the BCR toward the effluent zone.

Note that these values apply to the substrate volume in the bench cell BCR reactors which were only about $28 \mathrm{~cm}$ thick which is assumed to represent a typical BCR "reaction front" implied above. The substrate thickness in a full-scale BCR would be much greater and the longevity would be proportionately longer. For example, the longevity of a substrate layer $168 \mathrm{~cm}(1.7 \mathrm{~m})$ thick 
comprised of the BCR 2 mixture (wood, straw, and limestone) would be 31 years $(168 \mathrm{~cm} / 28 \mathrm{~cm}$ x 5.2 years $=31$ years).

This value is consistent with the longevity estimates at other mining sites (ITRC, 2013). The longevity value for a straw-dominated substrate (BCR 1) may be too short to be worth considering for full-scale design as the retrofitting event frequency would impose a significant burden on operation and maintenance economics.

The superiority of the BCR 3 substrate's longevity is believed to be due to the relative abundance of wood pellets (which exhibit a high "energy density" and high carbon content) compared to the amount of wood in the BCR 2 substrate. The degradation kinetics of woody materials in BCR substrates is typically slower than substrates containing straw or hay as inferred from "non-wood" substrate data in Seyler et al. (2003). Based on the sulfate-reduction rates, it appears that the biochar in the BCR 3 substrate mixture may have improved the carbon consumption kinetics to almost match those observed in BCR 1.

Table 4. BCR Cells Substrate Longevity.

\begin{tabular}{cccc}
\hline BCR & $\begin{array}{c}\text { Carbon } \\
\mathrm{kg}\end{array}$ & $\begin{array}{c}\text { Average Carbon } \\
\text { Consumption (g/day) }\end{array}$ & $\begin{array}{c}\text { Longevity } \\
\text { years }\end{array}$ \\
\hline 1 & 0.4 & 0.16 & 3.0 \\
2 & 0.6 & 0.11 & 5.2 \\
3 & 1.2 & 0.13 & 9.1 \\
\hline
\end{tabular}

$\underline{\text { BCRs and SPUs Autopsies }}$

At the end of the bench scale testing, BCRs 1, 2 and 3, and SPUs 1 and 2 were disassembled by Sovereign and Solfatara personnel to examine the substrate. Accumulations of elemental sulfur were observed on the upper substrate layer in all the BCRs. This is likely the result of oxidation of sulfide anion $\left(\mathrm{HS}^{-}\right)$under microaerophilic conditions. Figure 7 shows the accumulation of elemental sulfur on top of BCR 2.

In contrast, despite the solution data supporting active sulfate reduction in SPU 1, little if any elemental sulfur was found in the unit (Fig. 8). However, within the $\mathrm{pH}$ range exhibited by all of the SPUs, $\mathrm{HS}^{-}$oxidation would possibly be oxidized to thiosulfate, a soluble sulfur compound (Hughes et al., 2009). 


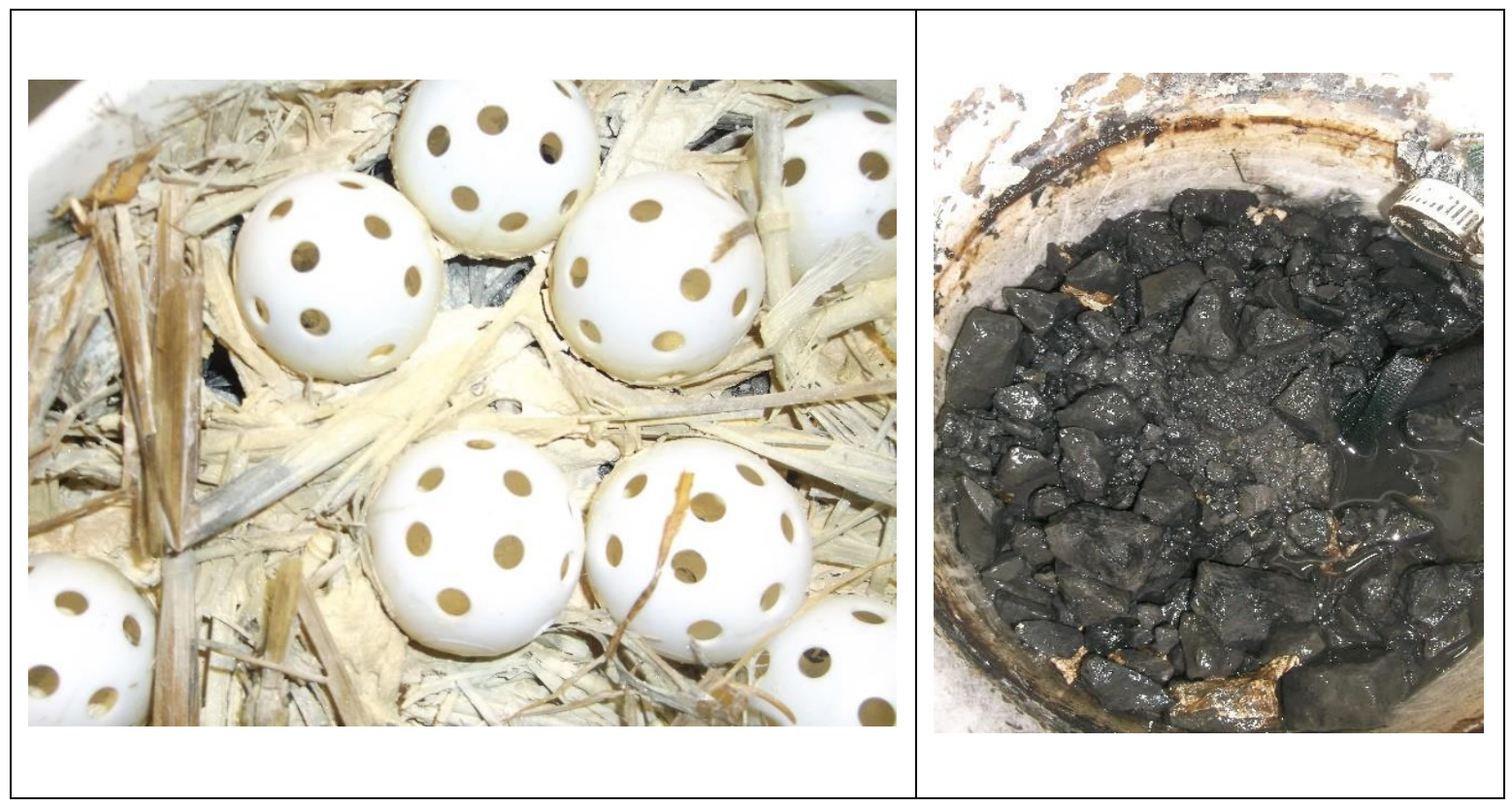

Figure 7. $\mathrm{S}^{0}$ on Top of BCR 2 Substrate.

Figure 8. Lack of $S^{0}$ in SPU 1.

\section{Conclusions}

Under the flow and temperature regimes used in this study, none of the three reactor mixtures resulted in sufficient microbial sulfate reduction to meet the defined discharge limit of $250 \mathrm{mg} / \mathrm{L}$. However, the solution and microbiological data support one view that the reactors were still maturing after 20 weeks and had not yet shown their full potential. Under a flow rate of 1,231 $\mathrm{ml} /$ day (the highest flow rate during the testing), the BCRs demonstrated final sulfate reduction rates of 1.3 to $1.6 \mathrm{~mol} \mathrm{SO}{ }_{4}^{-2} / \mathrm{m}^{3}$-day, with $\mathrm{BCR} 3$ having the highest rate. For comparison, sulfate removal efficiencies in the BCRs were 55\% (BCR 1), 57\% (BCR 2), and 67\% (BCR 3) during the final week of testing.

An additional sulfate reduction rate of 1.9 and $2.2 \mathrm{~mol} \mathrm{SO}_{4}^{-2} / \mathrm{m}^{3}$-day was achieved with SPU 1 (site native soil-rock) and SPU 2 (scrap metal, ZVI) during the final week of the testing. On a percentage basis (which considers primary sulfate removal in the BCRs), removal of "residual" sulfate in the SPUs was $35 \%$ and 37\%, for SPU 1 and SPU 2, respectively. The higher bulk sulfate removal kinetics in the SPUs compared to the BCRs was unexpected given that the hydraulic retention time in the much smaller SPU units was approximately $40 \%$ that of the larger BCRs and that only organic carbon transferred in BCR effluent was available to the microbial community. SPU 3 (magnetite material) proved an ineffective support as a substantial residual sulfate content 
obscured any interpretation as to impact on sulfate reduction and, in fact, appeared to become inhibitory in the final stages of the test.

If the thickness of the full-scale substrate layer is $1.7 \mathrm{~m}$ compared to $0.28 \mathrm{~m}$ used in the tests, the longevity of the BCR 2 mixture (wood, straw, and limestone) could be about 31 years based on bench-scale results, assuming the organic carbon decomposition rate remains constant within the "reaction zone" and is independent of the carbon concentration.

The BCR 2 mixture was selected to be used in the full-scale system. Although, BCR 3 was the "winner," this mixture was not selected due to the amount of biochar needed and the cost. Biochar availability was also a factor. A local vendor for this material was not available but this might change if a local demand could be demonstrated.

The BCRs/SPUs configurations produced a final effluent with slightly higher concentrations of $\mathrm{Ba}, \mathrm{Fe}, \mathrm{Mn}$, and $\mathrm{Tl}$ than the feed water. However, the concentrations of these analytes were near the limit of detection and may be considered experimental noise. The BCR 3 effluent Mn concentration is significantly higher than the influent. This may have been coincidental due to the high amounts of wood pellets which may have provided a slow-releasing source of manganese in the anaerobic conditions.

\section{$\underline{\text { References }}$}

Abram, J.W. and D.B. Nedwell, 1978. Hydrogen as a substrate for methanogenesis and sulphate reduction in anaerobic saltmarsh sediment. Archives of Microbiology, 117: 93-97. https://doi.org/10.1007/BF00689357

Blumenstein, E.P., R.J. Schipper, and J.J. Gusek, 2013. The construction and initial results of a demonstration passive treatment system for removing sulfate at a site on Vancouver Island, British Columbia. Presented at the 2013 Annual Meeting of the American Society for Mining and Reclamation, June. Laramie, WY. Abstract and PowerPoint presentation are available under the Past Meetings, 2013 Laramie http://www.asmr.us/Meetings/Past-Meetings

HACH Company, 2013. Bacteria, sulfate-reducing. Visual determination, semi-quantitative. DOC 316.53.01326, Edition 2, July 2013. 
Hughes, M.N., M. Centelles, and K.P. Moore, 2009. Making and working with hydrogen sulfide. The chemistry and generation of hydrogen sulfide in vitro and its measurement in vivo. Free Radi Biol Med 47(10): 1346-53. https://doi.org/10.1016/j.freeradbiomed.2009.09.018

Interstate Technology Regulatory Council (ITRC), 2013. Biochemical Reactors for MiningInfluenced Water. Accessed April, 2017.

http://www.itrcweb.org/BCR-1/Default.htm\#Welcome.htm\%3FTocPath\%3D1

Legrand, R., R.L. Henry, J.G. Bain, D.W. Blowes, J.F. Strunk Jr., and Y. Chai, 2014. Evaluation of organic amendments in a ZVI-enhanced PRB to treat metals and sulfate in water. Proceedings Tailings and Mine Waste 2014. Keystone, Colorado, USA. October 5-8, 2014.

Li, Gejing, D.R. Peacor, and E.J. Essene, 1998. The formation of sulfides during alteration of biotite to chlorite-corrensite. Clays and Clay Minerals, Vol. 46, No, 6, 649-657. https://doi.org/10.1346/CCMN.1998.0460605

Pelczar, Michael J., Jr., R.D. Reid, and E.C.S. Chan, 1977. Microbiology. McGraw-Hill Book Company, New York, 4th Edition. ISBN 0-0-049229-8. 952p.

Seyler, J., L. Figueroa, D. Ahmann, T.R. Wildeman, and M. Robustelli. 2003. "Effect of solid phase organic substrate characteristics on sulfate reducer activity and metal removal. In Passive Mine Drainage Treatment Systems. Proceedings American Society of Mining and Reclamation. 2003 pp 1112-1130. https://doi.org/10.21000/jasmr03011112

Wilkin, R.T. and M.S. McNeil, 2003. Laboratory evaluation of zero-valent iron to treat water impacted by acid mine drainage. Chemosphere, 53: 715-725. https://doi.org/10.1016/S0045$\underline{6535(03) 00512-5}$

Xu, Shengnan, D. Adhikari, R. Huang, H. Zhang, Y. Tang, E. Roden, and Y. Yang, 2016. Biocharfacilitated microbial reduction of hematite. Environ. Sci. Technol., https://doi.org/10.1021/acs.est.5b05517 